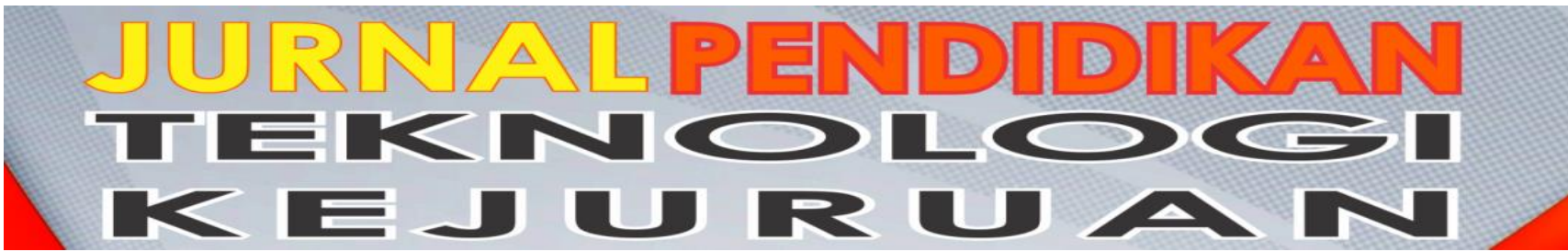

Vol. 4, No. 3 August 2021

P-ISSN: 2621-3273

E-ISSN: 2621-1548

\title{
Perencanaan Sistem Digitalisasi Promosi pada Objek Wisata Colo Muria Kabupaten Kudus
}

\author{
Ira Siti Mayashofa ${ }^{1}$, Putri Khoirin Nashiroh ${ }^{2 *}$ \\ ${ }^{1,2}$ Universitas Negeri Semarang \\ *Corresponding author, e-mail: putrikhoirin@mail.unnes.ac.id
}

\begin{abstract}
Tourism is a multidimensional activity that can show the identity of tourist attractions, one of which is the Colo Muria Tourism object which has local charm and wisdom that can be visited by tourists. This study aims to plan a digitalization system at the Colo Muria tourist attraction, Kudus Regency using Augmented Reality technology. The research method used is agile development. The steps of this research are Planning, Analysis, Design, Implementation, and Testing. Application testing using alpha testing in the form of functional testing (black box testing), portablity testing and beta testing in the form of usability testing (media expert tests and application user observer tests). The alpha test that tested the functionality aspect using the black box test showed that the application was running well and as planned. Beta testing was carried out by media experts and the percentage results were $80 \%$. From these results, it can be seen that the digitization system at the Colo Muria tourist attraction has good capabilities, so it can be declared worthy of being used as a means of tourism promotion. For beta testing using the respondent test, the final average score is $79 \%$, so it is included in the acceptable or feasible criteria for use. Suggestions put forward for further research are to add better animated travel videos and $3 D$ object animations so that the Colo Muria tourism object digitization system is more complete.
\end{abstract}

Keywords: System, Digitization, Promotion, Tourism, Augmented Reality, Android, Agile Development

Abstrak - Kepariwisataan merupakan suatu kegiatan bersifat multidimensional yang dapat menunjukan identitas tempat wisata, salah satu nya objek Wisata Colo Muria yang memiliki daya tarik dan kearifan lokal yang dapat dikunjungi oleh para wisatawan. Penelitian ini bertujuan untuk membuat perencanaan sistem digitalisasi pada objek wisata Colo Muria Kabupaten Kudus dengan menggunakan teknologi Augmented Reality. Metode penelitian yang digunakan adalah egile development. Langkah-langkah penelitian ini adalah Planning, Analysis, Design, Implementation, dan testing. Pada pengujian aplikasi, dilakukan dengan pengujian alpha berupa functional testing (uji black box), portablity testing dan pengujian beta berupa usablity testing (uji ahli media dan uji pengamat pengguna aplikasi). Pengujian alpha yang menguji aspek functionality menggunakan uji black box menunjukkan bahwa aplikasi berjalan dengan baik dan sesuai dengan yang direncanakan. Pengujian beta dilakukan oleh ahli media diperoleh hasil persentase $80 \%$. Dari hasil ini dapat diketahui bahwa sistem digitalisasi pada objek wisata colo muria memiliki kemampuan yang baik, sehingga dapat dinyatakan layak digunakan sebagai sarana promosi wisata. Untuk pengujian beta dengan menggunakan uji responden, mendapatkan skor rata-rata akhir sebesar 79\%, sehingga masuk dalam kriteria acceptable atau layak untuk digunakan. Saran yang diajukan untuk penelitian selanjutnya yaitu menambahkan video animasi perjalanan wisata dan animasi objek 3D yang lebih baik lagi agar sistem digitalisasi objek wisata colo muria lebih lengkap.

Kata kunci: Sistem, Digitalisasi, Promosi, Wisata, Augmented Reality, Android, Agile Development.

\section{PENDAHULUAN}

Kepariwisataan merupakan suatu kegiatan bersifat multidimensional yang dapat menunjukan identitas tempat wisata tersebut bahwa objek wisata Colo Muria merupakan salah satu tempat wisata yang sangat layak diperhitungkan untuk disinggahi sebagai tempat wisata baik bagi wisatawan dalam negeri maupun luar negeri.
Secara geografis objek wisata religi makam Sunan Muria terletak di Desa Colo, Kecamatan Dawe, Kabupaten Kudus, Jawa Tengah. Kawasan Makam Sunan Muria yang berada dikawasan Desa Colo memang menjadi daya tarik tersendiri bagi masyarakat muslim. Tempat wisata yang ada di Colo Muria ini memiliki potensi dan kearifan lokal yang dapat dikunjungi oleh para wisatawan, namun medan untuk menuju ke destinasi wisata cukup berat 
sehingga pengunjung merasa takut jika akan mengunjungi destinasi wisata.

Dengan pengembangan pembangunan Objek Wisata Colo, wisatawan tidak hanya dapat berziarah ke Makam Sunan Muria namun dapat pula beristirahat/menginap, berolahraga atau hanya sekedar melepaskan kepenatan di Taman Ria bersama keluarga dengan menikmati pemandangan dan kesejukan alam Pegunungan Muria. Objek Wisata Colo adalah salah satu objek wisata unggulan di Kabupaten Kudus. Objek tersebut terdiri dari Wisata Religi, Wisata Alam, Wisata Kuliner serta Oleh-oleh khas Colo diantaranya sebagai berikut: Makam dan Masjid Sunan Muria, Taman Ria Colo, Air Terjun Montel, Sumber Mata Air 3 Rasa, Air Gentong Peninggalan Sunan Muria, buah parijoto, jeruk pamelo, buah delima, pisang tanduk dan jangklong yang merupakan hasil bumi yang dijadikan oleh-oleh khas Colo Muria.

Kawasan Makam Sunan Muria yang berada dikawasan Desa Colo memang menjadi daya tarik tersendiri bagi masyarakat muslim. Lokasi Wisata Colo Muria masih minim informasi mengenai sejarah, fasilitas, lokasi ataupun informasi objek wisata yang ada. Informasi yang ada diinternet belum sepenuhnya menggambarkan detail mengenai informasi wisata khususnya objek wisata Colo Muria. Wujud pengembangan pariwisata secara terus-menerus mempromosikan tempat-tempat wisata potensial salah satunya yaitu wisata religi yang dikembangkan secara lebih optimal, untuk itu perlu adanya media informasi tentang objek wisata Colo Muria agar para wisatawan dapat mengetahui informasi terkait penjelasan objek wisata yang ada di Colo Muria. Pengembangan yang dilakukan dengan memanfaatkan ilmu pengetahuan dan teknologi (IPTEK) melalui perencanaan sistem digitalisasi promosi pada objek wisata Colo Muria. Perkembangan teknologi sangat pesat, terutama teknologi smartphone. Hal tersebut disebabkan karena masyarakat gemar menerima informasi atau berita dari smartphone dibanding media lain. Hal ini terbukti dari riset Indonesian Digital Association (IDA) yang dilansir techno.okezone.com menuliskan persentase pengguna smartphone mencapai 96\% sedangkan media lain seperti televisi $91 \%$, surat kabar $31 \%$ serta radio $15 \%$.

Teknologi smartphone yang bisa dimanfaatkan sebagai media informasi atau promosi adalah Augmented Reality (AR). Augmented reality secara umum merupakan sebuah teknologi yang dapat menampilkan suatu objek baik 2D maupun 3D dalam dunia maya menuju dunia yang nyata secara real-time (Azuma, 1997).

Augmented reality merupakan kombinasi antara dunia maya (virtual) dan dunia nyata (real) yang dibuat oleh komputer. Objek virtual yang berupa teks, animasi, model 3D atau video yang digabungkan dengan lingkungan sebenarnya sehingga pengguna merasakan objek virtual dilingkungannya (Hari dan hendrati, 2018).

Sistem Digitalisasi dalam bentuk teknologi Augmented reality $(A R)$ dapat digunakan sebagai media penyampai informasi tentang lokasi wisata tersebut. Teknologi AR dapat membantu tempat wisata yang dikunjungi lebih familiar ketika wisatawan mengunjungi objek wisata tersebut. Selain penggunaan AR sebagai media informasi, AR pun bisa digunakan sebagai media promosi dengan bentuk yang inovatif, kreatif dan interaktif. Bentuk media promosi interaktif AR memungkinkan pengguna untuk benar-benar terlibat, dengan begitu secara langsung menciptakan hubungan dengan pengguna. Augmented Reality dikembangkan sebagai bagian dari media informasi pariwisata untuk memberikan informasi tentang tujuan dari objek wisata serta menunjukkan potensinya untuk menjadi layanan perpariwisataan yang baru (Chung, et al., 2015).

Sistem Digitalisasi ini menggunakan Unity 3D untuk membangun antar muka dan vuforia sebagai engine untuk menganalisis marker dan memunculkan objek 3D. Hasil penerapan teknologi AR menarik dan efisien karena pengguna dapat melihat objek secara virtual dalam bentuk grafis 3D sehingga seolah-olah objek berada pada dunia nyata dengan bantuan telepon genggam yang bersistem operasi android (Rifa'i et al., 2014).

Dari beberapa uraian sebelumnya, Sistem digitalisasi menjadi solusi promosi secara optimal menggunakan teknologi Augmented Reality (AR). Pembuatan media sistem digitalisasi ini diharapkan dapat menampilkan informasi objek wisata yang ada di Kawasan Colo Muria Kabupaten Kudus, sehingga penyampaian informasi objek wisata sepenuhnya menggambarkan detail mengenai informasi wisata. Berdasarkan uraian di atas, maka peneliti mengangkat skripsi dengan judul "Perencanaan Sistem Digitalisasi Promosi pada Objek Wisata Colo Muria Kabupaten Kudus".

Tujuan penelitian yang dilakukan adalah untuk:

1. Melaksanakan Proses Pembuatan Sistem Digitalisasi Promosi pada Objek Wisata 
Colo Muria Kabupaten Kudus.

2. Melakukan Pengujian Hasil Perencanaan Sistem Digitalisasi Promosi pada Objek Wisata Colo Muria Kabupaten Kudus.

\section{METODE}

A. Waktu dan Tempat pelaksanaan

Waktu penelitian ini dilaksanakan pada bulan Juni 2020 sampai Agustus 2021. Lokasi penelitian dilaksanakan di kawasan wisata Colo Muria, Kecamatan Dawe Kabupaten Kudus dan Universitas Negeri Semarang.

B. Desain penelitian

Model pengembangan software yang digunakan pada penelitian ini adalah Agile Software Development. Proses metode ini dapat di lihat pada Gambar 1 ini.

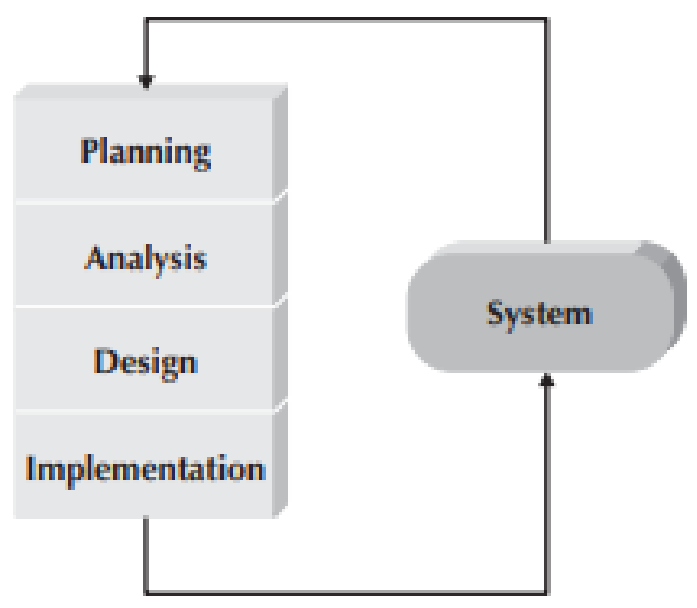

Gambar 1 Metode Agile Development

Tahapan-tahapan prosedur yang digunakan dalam perencanaan sistem digitalisasi promosi objek wisata Colo Muria hingga menjadi produk aplikasi antara lain: planning, analysis, design, implementation, testing.

\section{Planning}

Sistem digitalisasi berfokus pada kecocokan visualisasi objek 3D wisata colo muria kabupaten kudus yang dapat menjelaskan gambaran informasi tentang beberapa objek wisata Colo Muria dari segi destinasi tempat dan oleh-oleh.

\section{Analisys}

Tahap analisis ini merupakan identifikasi kebutuhan perencanaan sistem digitalisasi bertujuan agar kebutuhan-kebutuhan seperti alat dan bahan yang diperlukan sebelum pembuatan aplikasi dapat dipenuhi. Kebutuhan alat dan bahan dapat dilihat pada tabel 1 .
Tabel 1. alat dan bahan

\begin{tabular}{|c|c|c|}
\hline No & Alat dan bahan & Spesifikasi \\
\hline 1 & Laptop Asus X407UF & $\begin{array}{l}\text { Intel Core i5, RAM 8GB, } \\
\text { SSD NVMe. }\end{array}$ \\
\hline 2 & Unity Hub & Unity 2018.4.26f1 (64-bit) \\
\hline 3 & Android Studio & $\begin{array}{l}\text { android-studio-ide- } \\
\text { 193.6626763-windows }\end{array}$ \\
\hline 4 & Corel draw X7 & 2.0 \\
\hline 5 & Blender & Blender-2.82-windows64 \\
\hline 6 & $\begin{array}{l}\text { Software } \\
\text { Office }\end{array}$ & $\mathrm{t}_{2013,64 \mathrm{bit}}$ \\
\hline
\end{tabular}

\section{Desain}

Desain atau perancangan merupakan tahap perancangan aplikasi. Proses pembuatan desain aplikasi Augmented reality ini dilakukan, meliputi perancangan tampilan Use Case Diagram dan desain tampilan aplikasi.

a. Use case diagram

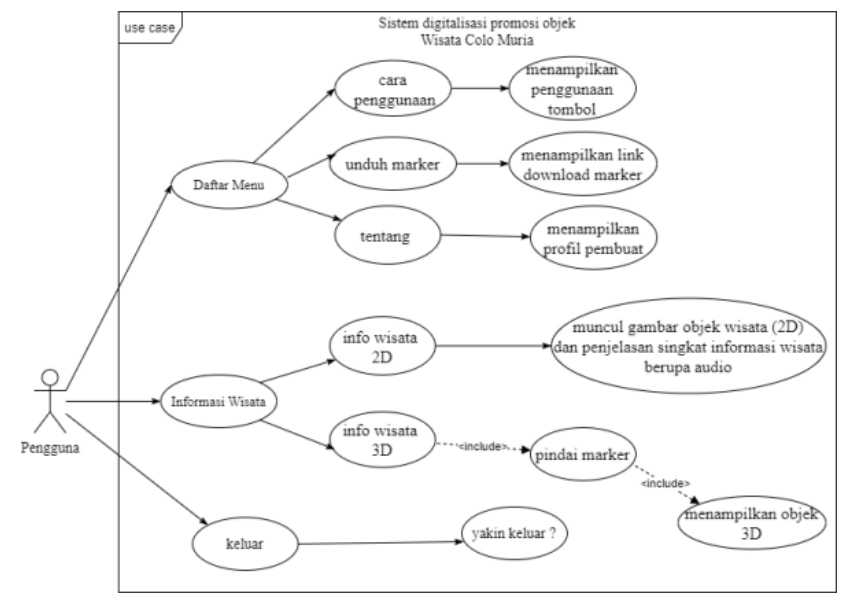

Gambar 1. Use Case Diagram Aplikasi

b. Desain tampilan media

Desain antarmuka atau user interface merupakan tahap pembuatan desain tampilan yang sangat penting dalam pengembangan media informasi berbasis aplikasi. Dalam tahap ini digambarkan tata letak setiap tombol, judul, materi serta komponen-komponen yang ada dalam media informasi.

\section{Implementation}

Desain objek destinasi dan hasil bumi atau oleholeh khas Colo Muria yang ada dalam bentuk 3D diterapkan dalam bentuk teknologi augmented Reality. Desain aplikasi Augmented reality yang telah ditentukan. Penulisan kode pada aplikasi Augmented reality ini menggunakan UnityHub versi unity 2018.4.26f1 (64-bit) yang sudah dilengkapi dengan vuforia dan digabungkan menggunakan android studio untuk Build ke dalam 
bentuk aplikasi android. Implementasi aplikasi Augmented reality berupa penulisan kode serta pembuatan tampilan sesuai desain aplikasi. Metode marker akan digunakan pada penelitian ini karena dilandasi oleh banyaknya penelitian yang ada metode marker lebih efektif dan lebih baik jika digunakan untuk media promosi (R. A. Setyawan dan A. Dzikri, 2016)

\section{Testing}

Tujuan testing adalah menemukan kesalahankesalahan terhadap sistem tersebut untuk kemudian bisa diperbaiki. Setelah perencanaan sistem digitalisasi promosi objek wisata Colo Muria selesai, maka perlu dilakukan pengujian, pengujian yang dilakukan yaitu pengujian alpha menggunakan black box testing dan beta dengan standar kelayakan menurut ISO 9126 yang terdapat enam aspek yaitu Functionality, Reliability, Usability, Efficiency, maintainability, Portability. Pada penelitian perencanaan sistem digitalisasi promosi objek wisata Colo Muria ini aspek yg diujikan yakni Functionality, Usability, dan Portability.

\section{Pengujian alpha}

Pengujian alpha adalah pengujian yang dilakukan dengan mencari kesalahan yang ada pada sebuah sistem yang berfokus pada persyaratan fungsional perangkat lunak yang dibuat (Setiawan et al., 2016: 32). Pengujian alpha dinyatakan berhasil apabila aplikasi berjalan dengan baik sehingga aplikasi dapat diuji pada tahap selanjutnya (Prabowo et al., 2015: 53). Pengujian Alpha dilakukan dengan Black box testing yang berfokus pada kesesuaian aplikasi. Pengujian Black box hanya mengamati hasil dari eksekusi pada aplikasi yang dibuat, jadi fokus pada pengujian ini adalah pada pengujian fungsionalitas (Suryanto et al., 2018: 36).

2. Pengujian betha

Pengujian beta dilakukan guna mengetahui sejauh mana kualitas dari sebuah sistem yang dibuat, apakah sudah memenuhi harapan atau belum (Setiawan et al., 2016). Pengujian beta melakukan penelitian terhadap ahli materi dan pengamat pengguna aplikasi (Responden) di mana tidak di kontrol dan melibatkan pengembang lagi (Pressman \& Maxim, 2015)

\section{Parameter penelitian}

Penelitian ini ditentukan dari validasi media oleh ahli media pada aspek functionality, usability, dan portability serta penggujian terhadap pengguna System Usability Scale (SUS).Validasi media dalam penelitian ini menggunakan kuesioner. Kuesioner diberikan kepada ahli dalam bidang rekayasa perangkat lunak, sedangkan penggujian System
Usability Scale (SUS) sasarannya adalah pengurus objek Colo Muria dan para wisatawan Colo Muria baik yang sudah pernah berkunjung maupun yang belum.

D. Teknik pengumpulan data

Teknik pengumpulan data pada penelitian ini menggunakan angket atau kuesioner. Angket atau kuesioner sendiri merupakan teknik pengumpulan data di mana partisipan responden mengisi pertanyaan atau pernyataan kemudian setelah diisi dengan lengkap mengembalikan kepada peneliti (Sugiyono, 2017: 216).

E. Teknik analisis data

1. Teknik analisis alpha

Pengujian alpha yang dilakukan dengan Black box testing, analisis yang digunakan adalah dengan skala Guttman sebagai pengukur instrumen, di mana skala pengukuran dengan tipe ini akan mendapatkan jawaban tegas 'berhasiltidak" (Sugiyono, 2017).

2. Teknik analisis betha

a. Analisis pengujian validitas media

Pada analisis validitas ahli media ini dihitung menggunakan Skala Likert sebagai instrumen pengukuran, di mana jawaban tiap instrumennya mempunyai gradasi dari sangat positif sampai sangat negatif. Menurut Sugiyono, (2017: 165). Berikut pedoman skor pedoman penilaian dapat dilihat pada tabel 2 .

Tabel 2. skala likert pada skor jawaban

\begin{tabular}{lr}
\hline Jawaban & S \\
\hline Sangat Setuju/Sangat Baik & 4 \\
Setuju/Baik & 3 \\
Tidak Setuju/Tidak Baik & 2 \\
Sangat Tidak Setuju/Sangat Tidak Baik 1
\end{tabular}

Hasil data dari angket yang telah di konversi dengan Skala Likert selanjutnya dihitung dengan cara dijumlahkan, dibandingkan dengan jumlah yang diharapkan dan diperoleh persentase.

\footnotetext{
Presentase $=\frac{\text { Skor yang diperoleh }}{\text { Skor maksimum }} \times 100 \%$

Presentase yang telah diketahui, kemudian digolongkan ke dalam kriteria penilaian yang terlihat pada Tabel 3.
} 
Tabel 3. Skala presentase kelayakan

\begin{tabular}{ll}
\hline Presentase & Kriteria \\
\hline $81,25 \%>$ skor $\leq 100 \%$ & Sangat Layak \\
$62,50 \%>$ skor $\leq 81,25 \%$ & Layak \\
$43,75 \%>$ skor $\leq 62,50 \%$ & Kurang Layak \\
$25 \% \geq$ skor $\leq 43,75 \%$ & Tidak Layak
\end{tabular}

\section{b. Analisis System Usability Scale (SUS)}

Analisis yang dilakukan pada hasil instrumen SUS menggunakan skala Likert sebagai pengukuran dalam instrumen, pada tipe pengukuran ini jawaban setiap item instrumennya mempunyai rentang perbedaan dari sangat positif sampai sangat negatif (Sugiyono, 2017: 165). Rentang Skor Kuesioner SUS (System Usability Scale) dapat dilihat pada tabel 4.

Tabel 4. Rentang Skor Kuesioner SUS

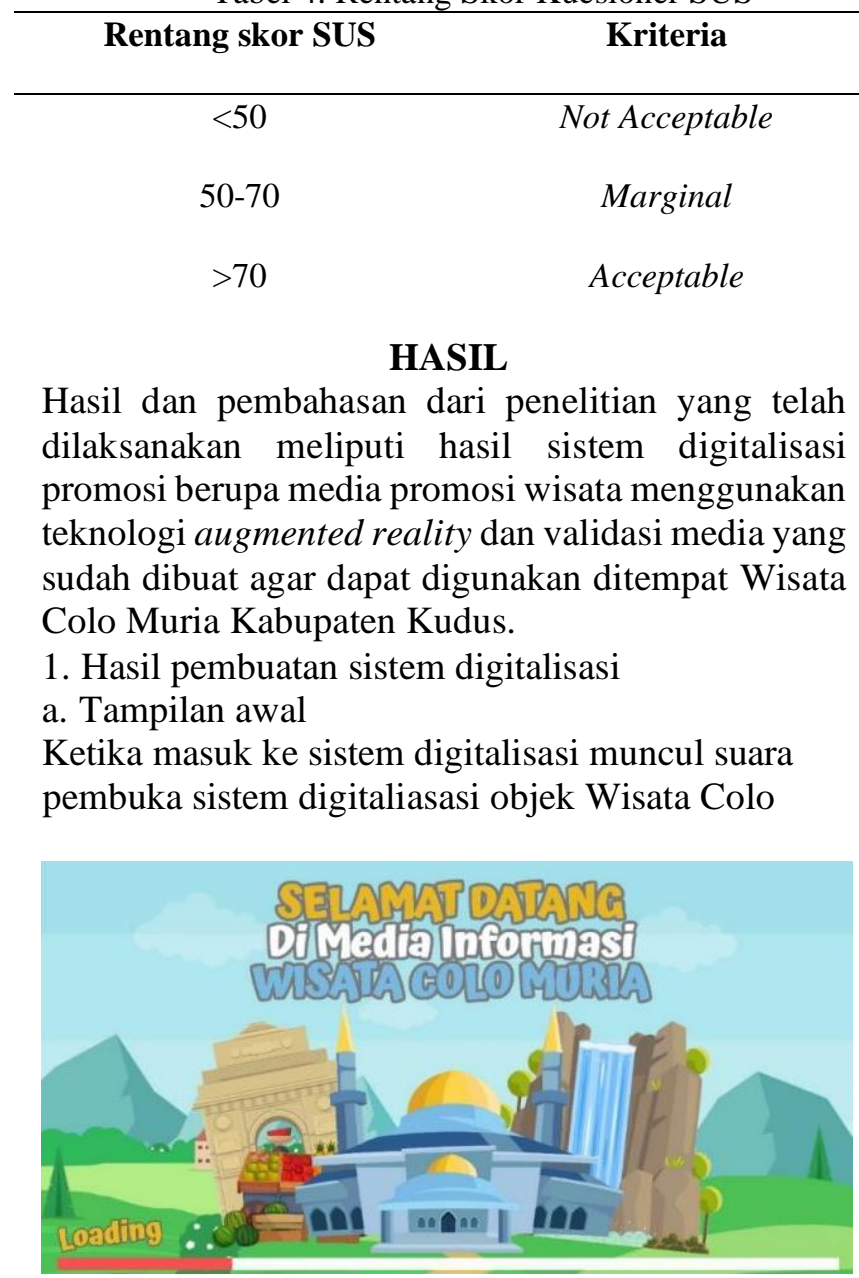

Gambar 2. Tampilan awal Sistem Digitalisasi b. Tampilan beranda

Halaman beranda terdapat 2 menu utama. Menu yang pertama yakni tombol daftar menu yang memuat cara penggunaan, unduh marker, dan profil pengembang, sedangkan menu yang kedua yakni informasi wisata yang memuat seputar informasi wisata dalam bentuk 2D dan 3D.

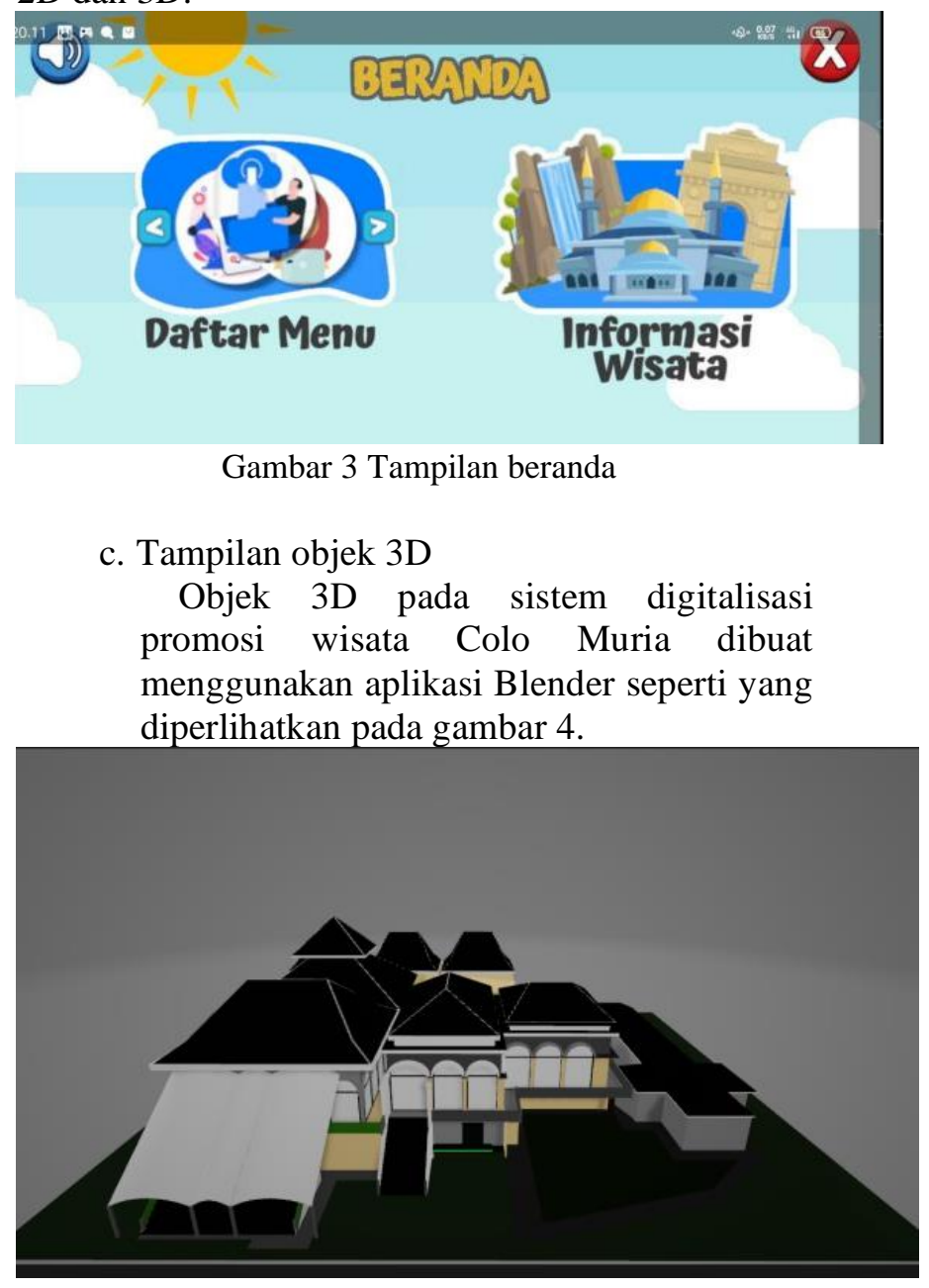

Gambar 4. tampilan 3D objek wisata

Proses terakhir dalam pembuatan aplikasi Sistem Digitalisasi yaitu build aplikasi di pada Unity 3D ke Android agar aplikasi dapat diuji langsung dan digunakan di perangkat Android.

\section{DISKUSI}

Proses terakhir dalam pembuatan aplikasi Sistem Digitalisasi yaitu build aplikasi di pada Unity 3D ke Android agar aplikasi dapat diuji langsung dan digunakan di perangkat Android.

\section{Pembahasan Validasi sistem digitalisasi}

a. Pengujian alpha

Pengujian alpha lebih difokuskan pada aspek functionality dengan menggunakan uji black box untuk menentukan apakah aplikasi yang dibuat sudah sesuai dengan yang direncanakan atau belum. Pengujian ini dilakukan menggunakan smartphone 
Oppo A5 2020 dengan menguji 12 skenario uji. Dari hasil pengujian 12 skenario uji diperoleh 12 dinyatakan seluruhnya berhasil, dengan persentase diperoleh $100 \%$. Berdasarkan hasil tersebut dinyatakan bahwa semua menu, fungsi maupun tombol pada aplikasi dapat digunakan dengan baik dan tidak di dapatkan error karena semua tombol dan scene berfungsi dengan baik.

Pengujian black box dalam bentuk pengujian portability juga dilakukan dengan cara menginstall dan menjalankan aplikasi ini dengan menggunakan beberapa android dengan versi OS dan prosessor yang berbeda yaitu versi Nougat, Pie dan Android 10. Dari hasil pengujian tersebut didapatkan hasil presentase perhitungan $100 \%$. Dari hasil tersebut dapat ditarik kesimpulan bahwa tidak ditemukan error dan aplikasi berjalan dengan lancar ketika digunakan di beberapa android dengan versi yang berbeda.

\section{b. Pengujian betha}

1. Validitas media

Pengujian validitas media yang diuji oleh dengan penilaian terbagi menjadi 3 aspek, yaitu aspek Functionality, aspek Usability, dan aspek Portability menghasilkan persentase kelayakan validitas ahli media memperoleh nilai persentase $80 \%$, maka dapat disimpulkan bahwa sistem digitalisasi promosi objek wisata colo muria dinyatakan sangat layak.

\section{Pengujian SUS (System Usability Scale)}

Pengujian SUS dilakukan untuk mengetahui kelayakan sistem digitalisasi menurut pengguna. Pengujian ini juga menggunakan angket kuesioner sebagai medianya, dengan responden yang berjumlah 40 orang baik yang sudah pernah berkunjung atau yang belum pernah mengunjungi tempat wisata colo muria. Pengujian dilakukan dengan melakukan pengamatan pada pengguna dalam menggunakansistem digitalisasi, untuk kemudian angket diisi oleh pengguna sesuai pengamatan yang dilakukan. Setelah dilakukan pengujian didapatkan hasil persentase dengan responden 40 pengguna diperoleh 79\%. Dari angka tersebut dapat ditarik kesimpulan uji aspek usability dinyatakan "Layak".

\section{KESIMPULAN}

Berdasarkan hasil penelitian dan pembahasan yang telah dilakukan mengenai "Sistem Digitalisasi Promosi pada Objek Wisata Colo Muria Kabupaten Kudus" dapat diambil kesimpulan sebagai berikut:

a. Sistem Digitalisasi Promosi pada Objek Wisata Colo Muria Kabupaten Kudus berbasis Android ini menggunakan teknologi Augmented Reality berhasil dibuat dengan metode agile development yang terbagi menjadi beberapa tahapan yaitu planning, analysis, design, implementation, dan testing. Dalam pembuatan background dan tombol menggunakan software Adobe Photoshop, dan Adobe Ilustrator. Untuk pembuatan karakter dan bangunan menggunakan software Blender 3D, serta seluruh bahan yang sudah jadi dibangun menjadi aplikasi yang utuh menggunakan Unity Game Engine dan Vuforia.

b. Pengujian alpha yang menguji aspek functionality menggunakan uji black box menunjukkan bahwa aplikasi berjalan dengan baik dan sesuai dengan yang direncanakan. Pengujian betha dilakukan oleh ahli media untuk mengetahui kualitas dan kelayakan aplikasi berdasarkan aspek pengujian functionality, aspek usability, dan aspek portability. Berdasarkan penilaian ahli media diperoleh hasil persentase $80 \%$. Di mana aspek Functionality $86 \%$, aspek Usability $78 \%$, dan aspek Portability $80 \%$. Dari hasil ini dapat diketahui bahwa sistem digitalisasi pada objek wisata colo muria memiliki kemampuan yang baik dalam menampilkan informasi objek wisata dalam bentuk digital dengan menarik, sehingga dapat dinyatakan layak digunakan sebagai sarana promosi wisata. Untuk pengujian beta dengan menggunakan uji responden, mendapatkan skor rata-rata akhir sebesar $79 \%$, sehingga masuk dalam kriteria acceptable atau layak untuk digunakan. Hasil respons pengguna menunjukkan hasil yang sangat positif, sehingga dapat diketahui bahwa kualitas aplikasi dalam menampilkan informasi sudah sangat baik dan pengguna tertarik untuk menggunakan sistem digitalisasi pada objek wisata colo muria.

\section{DAFTAR PUSTAKA}

Azuma, Ronald T. (1997). A Survey of Augmented Reality. Presence: Teleoperators and Virtual Environments 6 (4): 2,356.

Chung, N., Han, H. \& Joun, Y. (2015). Tourists intention to visit destination: Role of augmented reality applications for heritage site. Computers in Human Behavior.

Hari F, Diansari O. (2018). Pemanfaatan Augmented Reality Untuk Pengenalan Landmark Pariwisata Kota Surakarta. 12(1):7-10.

Prabowo, R., Listyorini, T., \& Jazuli, A. (2015). Pengenalan Rumah Adat Indonesia Berbasis Augmented Reality Dengan Memanfaatkan 
KTP Sebagai Marker. Prosiding SNATIF, 2(2), 51-58.https://doi.org/10.1145/2656433

Pressman, R. S., \& Maxim, B. R. 2015. Software Engineering : A Practitioner's Approach, Eighth Edition. ACM SIGSOFT Software Engineering Notes. https://doi.org/10.1145/1226816.1226822.

R. A. Setyawan dan A. Dzikri. (2016). Analisis Penggunaan Metode Marker Tracking Pada Augmented Reality Alat Musik Tradisional Jawa Tengah," Simetris J. Tek. Mesin, Elektro dan Ilmu Komputer., vol. 7, no. 1, p. 295.

Rifa'il, Muhammad, dkk. (2014). Penerapan Teknologi Augmented Reality pada Aplikasi Katalog Rumah Berbasis Android. Prosiding SNATIF.

Setiawan, E., Syaripudin, U., \& Gerhana, Y. A. (2016). Implementasi Teknologi Augmented Reality Pada Buku Panduan Wudhu Berbasis Mobile Android. Jurnal Online Informatika (JOIN), 1(1), 28-33.

Sugiyono. (2012). Metode Penelitian Kuantitatif Kualitatif dan $R \& D$. Bandung: Alfabeta. Sudaryono, Untung Raharja Suryo Guritno. Theory and Application of IT ResearchMetodologi Penelitian Teknologi Informasi, 1st ed. Yogyakarta: Andi, 2011.

Sugiyono. (2017). Metode Penelitian dan Pengembangan (Research and Development/R\&D). Bandung: Alfabeta. https://doi.org/10.1016/j.drudis.2010.11.005.

Sugiyono. (2018). Metode Penelitian Kuantitatif. Bandung: Alfabeta.

Suryanto, A., Kusumawati, D. A., \& Sanhoury, I. M. H. (2018). Development of Augmented Reality Technology Based Learning Media of Lathe Machines. Jurnal Pendidikan Teknologi dan Kejuruan, 24(1), 32-38. https://doi.org/10.21831/jptk.v24i1.18245 